http://jmscr.igmpublication.org/home/

ISSN (e)-2347-176x ISSN (p) 2455-0450

crossref DOI: https://dx.doi.org/10.18535/jmscr/v7i7.91

\title{
A Dose Response Study of Intrathecal Fentanyl Added to 0.5\% Ropivacaine in Pediatric Spinal Anesthesia for Infraumblical Surgeries- A Double Blinded Randomised Study
}

\author{
Authors \\ Kanta Bhati ${ }^{1}$, Deepika Hatila ${ }^{2 *}$ \\ ${ }^{1}$ Professor and Head, ${ }^{2}$ Resident \\ Department of Anaesthesia, Sardar Patel Medical College \& AGH, Bikaner, Rajasthan \\ *Corresponding Author \\ Deepika Hatila
}

Resident, Department of Anaesthesia, Sardar Patel Medical College \& AGH, Bikaner, Rajasthan, India

\begin{abstract}
Abstarct
Aim and Objectives: The aim was to compare adequacy of anesthesia and analgesia provided by two different doses of Fentanyl (0.2 and $0.4 \mathrm{mcg} / \mathrm{kg})$ as an adjuvant to $0.5 \%$ Isobaric Ropivacaine $(0.5 \mathrm{mg} / \mathrm{kg})$ in pediatric spinal anesthesia for infra-umbilical surgeries.

Materials and Methods: This prospective, randomized, double blind, single center based study was conducted on 90 patients of either sex, aged 3-10 year, ASA grade I and II, undergoing elective infraumbilical surgeries. All patients were divided randomly into three groups- Group $R$ - Inj.0.5\% Ropivacaine $0.5 \mathrm{mg} / \mathrm{kg}$, Group RF0.2- Inj.0.5\%Ropivacaine $0.5 \mathrm{mg} / \mathrm{kg}+$ Inj.Fentanyl $0.2 \mathrm{mcg} / \mathrm{kg}$ and Group RF0.4- Inj.0.5\%Ropivacaine $0.5 \mathrm{mg} / \mathrm{kg}+$ Inj.Fentanyl $0.4 \mathrm{mcg} / \mathrm{kg}$. Sensory-motor blockade characteristics and duration of analgesia were primary outcomes. Hemodynamic variables, success rate and total analgesic consumption were secondary outcomes.

Result: Onset and peak of sensory blockade was faster Fentanyl groups. Duration of analgesia was

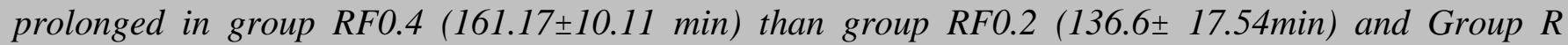
(117.5 $\pm 14.28 \mathrm{~min})$. Motor block characteristics were comparable. Total analgesic consumption in first 24 hours was significantly decreased in group RF0.4 (653.2 $\pm 184.96 \mathrm{mg})$ compared to group RF0.2 $(754.4 \pm 197.31 \mathrm{mg})$ and group $R(843.75 \pm 239.75 \mathrm{mg})$. Hemodynamic stability was seen in all groups. Incidence of nausea-vomiting and pruritus increased with higher dose of fentanyl.

Conclusion: We concluded that intrathecal Fentanyl as an adjuvant to Ropivacaine prolongs the duration and quality of analgesia without significant effect on motor block. Although increasing the dose of fentanyl from $0.2 \mu \mathrm{g} / \mathrm{kg}$ to $0.4 \mu \mathrm{g} / \mathrm{kg}$ improves quality of block and increases duration of analgesia but the incidence of nausea-vomiting and pruritus are also increases.

Keywords: Pediatric spinal anesthesia, Ropivacaine, Fentanyl.
\end{abstract}

\section{Introduction}

Spinal anesthesia has been a part of pediatric anesthesia for more than 100 years. Despite a long published history this technique was restricted to small number of practitioners in few specialized pediatric centers until recently. Increasing 
awareness regarding the deleterious effect of postoperative pain on the recovery of patients led to the increased regional anesthesia use in pediatric patients. It is an excellent method for children ${ }^{1}$. In addition to provide potent perioperative analgesia, it reduces - the stress response, systemic analgesic requirements, opioid-related side effects and general anesthesia requirements.

An important concern with the use of intrathecal local anesthetic in infants and children is the risk of toxicity ${ }^{2}$. This age group is particularly prone to direct toxicity of local anesthetic on the spinal cord when administered in large dose.

Ropivacaine is an amide local anesthetic with properties closely similar to those of Bupivacaine ${ }^{3}$ but less cardio-toxic. The lipid solubility of Ropivacaine is less than Bupivacaine, which explains its somewhat lower potency. In children shorter duration of spinal blockade is attributed to increase cardiac output, local vascularity and CSF volume which lead to increase systemic absorption. Intrathecal adjuncts are often used to enhance the duration of neuraxial anesthesia ${ }^{4}$ Fentanyl an opioid has synergistic analgesic effect in adult surgical and obstetric population ${ }^{5}$. Ropivacaine with Fentanyl found to be better combination for infra-umbilical pediatric surgeries under caudal anesthesia as an adjuvant to general anesthesia or as a sole technique with chances of less complication and high success rate.

The dose of intrathecal opioid added to the local anesthetic is important not only for the quality of surgical anesthesia but also for the onset and duration of the block. Intrathecal fentanyl is associated with side effects such as pruritus, nausea/vomiting, and respiratory depression ${ }^{6}$. The evidence regarding appropriate dose of intrathecal fentanyl is still under investigation. In this study we compare the efficacy and safety of two different doses of fentanyl (0.2and $0.4 \mathrm{mcg} / \mathrm{kg}$ ) as an adjuvant to $0.5 \%$ isobaric Ropivacaine $(0.5 \mathrm{mg} / \mathrm{kg})$ for infra-umbilical surgeries in children.

\section{Method}

After approval by the Institute Ethical Committee and written informed consent from patient's parent or caretaker, this prospective randomized controlled parallel group hospital based study was performed on 90 ASA Grade I \& II patients of both sexes aged 3-10 years posted for elective infra-umbilical surgeries. Patient allergic to study drugs, pre-existing neuromuscular disorder or spinal deformities, coagulation defect, local site infection, raised ICT were excluded from study.

On the day prior to surgery a thorough clinical examination of the patients was performed including history, general physical examination, systemic and local examination of lumber spine. Children were randomly divided into 3 groups 30 patients in each. Group $\mathrm{R}$ received Inj.0.5\% Ropivacaine $0.5 \mathrm{mg} / \mathrm{kg}$, Group RF0.2 received Inj. $0.5 \%$ Ropivacaine $0.5 \mathrm{mg} / \mathrm{kg}+$ Inj.Fentanyl 0.2 $\mathrm{mcg} / \mathrm{kg}$ and Group RF0.4 received Inj.0.5\% Ropivacaine $0.5 \mathrm{mg} / \mathrm{kg}+$ Inj.Fentanyl $0.4 \mathrm{mcg} / \mathrm{kg}$. EMLA cream was applied at venipuncture and lumbar puncture site. Most of the children were counseled slowly to the operating room. All the children were preloaded with isolyte-P $10 \mathrm{ml} / \mathrm{kg}$ and premedicated with inj.Midazolam IV $0.02 \mathrm{mg} / \mathrm{kg}$. Pulse-oximeter probe and NIBP cuff were applied preferably to lower extremities to avoid disturbance to child during surgery. Baseline vitals were recorded and monitored throughout the procedure.

Intravenous inj.Glycopyrrolate $5 \mathrm{mcg} / \mathrm{kg}$ and inj.Ketamine IV $0.5 \mathrm{mg} / \mathrm{kg}$ were given for sedation to maintain immobility while performing subarachnoid block. Under strict aseptic precautions sub arachnoid block performed in lateral position at L4-L5 level with a 27-gauge spinal needle. After confirmation of CSF free flow, predetermined dose of study drug was injected and the child immediately turned supine. Caution was taken no one elevates the lower extremities. Blood pressure (BP) and heart rate (HR) was observed just after the SAB and then every $5 \mathrm{~min}$ up to $30 \mathrm{~min}$, thereafter every $15 \mathrm{~min}$ till the end of operation. 


\section{Block Assessment}

Sensory onset was considered when patient does not feel pin prick with a $22 \mathrm{G}$ needle at T10 level. Highest level of sensory block and duration of sensory block (regression to T12) was noted.
The duration of analgesia was defined as the time interval between spinal drug injection and the first analgesic requirement. If the child complained of pain or if the observational pain score was $>/=3$, the child was given IV Paracetamol $15 \mathrm{mg} / \mathrm{kg}$ as a rescue analgesic.

\begin{tabular}{|c|c|c|}
\hline \multicolumn{3}{|c|}{ Table 1: Observation Pain Scale } \\
\hline & Criteria & Score \\
\hline Heart rate & $\begin{array}{l}>10 \% \text { to }<20 \% \text { of preoperative } \\
20 \% \text { to } 30 \% \text { of preoperative level } \\
>30 \% \text { of preoperative level }\end{array}$ & $\begin{array}{l}0 \\
1 \\
2\end{array}$ \\
\hline Blood pressure & $\begin{array}{l}>10 \% \text { to }<20 \% \text { of preoperative } \\
20 \% \text { to } 30 \% \text { of preoperative level } \\
>30 \% \text { of preoperative level }\end{array}$ & $\begin{array}{l}0 \\
1 \\
2\end{array}$ \\
\hline Crying & $\begin{array}{l}\text { Not crying } \\
\text { Crying but responds to tender loving care } \\
\text { Crying and does not respond to tender loving }\end{array}$ & $\begin{array}{l}0 \\
1 \\
2\end{array}$ \\
\hline
\end{tabular}

Motor block was determined according to Bromage scale for lower extremities on a 3-point scale:

- 0-Patient is able to move the hip, knee and ankle

- 1-Patient is unable to move the hip but able to move the knee and ankle

- 2-Patient is unable to move the hip and knee but able to move the ankle

- 3-Patient is unable to move the hip, knee and ankle.

Onset of motor blockade was considered when there is Grade 1 motor blockade. Duration of motor block was defined as the time interval between the end of drug administration and the recovery of complete motor function of the leg and foot.

Post-operatively vitals and block characteristics were assessed every 30 min after surgery until the complete recovery of motor and sensory function.
The study was discontinued after 24 hrs. All patients were observed for any side-effects and treated with appropriate measures.

\section{Statistical Analysis}

For data collection pre structured pre tested proforma was used and for data analysis Microsoft excel and statistical software SPSS version 22.0 was used. Data were analyzed with the help of percentage, mean, SD in the form of tables, diagrams and tests of significance (Chi-square test, student $\mathrm{t}$ test and ANOVA) were applied wherever required.

\section{Results}

Demographical data were statistically comparable. The differences of basic vital parameters and duration of surgery were found statistically insignificant (p-value>0.05). We achieved successful spinal anesthesia in $92 \%$ patients in the first attempt, rest required a second attempt.

\begin{tabular}{|c|c|c|c|c|}
\hline Character & Group-R & Group-RF0.2 & Group- RF0.4 & p-value \\
\hline & Mean \pm SD & Mean \pm SD & Mean \pm SD & \\
\hline Age & $6.1 \pm 2.28$ & $6.0 \pm 2.04$ & $6.73 \pm 2.05$ & 0.82 \\
\hline Weight & $19 \pm 5.4$ & $18 \pm 3$ & $20.4 \pm 4.53$ & 0.724 \\
\hline $\mathrm{Sex}-\mathrm{M} / \mathrm{F}$ & $27 / 3$ & $26 / 4$ & $28 / 2$ & - \\
\hline Duration of surgery (min.) & $30.6 \pm 8.71$ & $28.16 \pm 9$ & $26.93 \pm 6.676$ & 0.41 \\
\hline
\end{tabular}

Data are expressed as mean \pm standard deviation except gender distribution which is in ratio (M/F-Male/Female) 
Mean onset time of sensory blockade was earliest in group RF0.4 as compared to group RF0.2 and group $\mathrm{R}$ ( $\mathrm{p}$-value <0.05). Duration of sensory blockade was longer in group RF0.2 compared to group R and group RF0.4 as compared with group RF0.2 and R (p-value 0.001) (Table-3). Onset and duration of motor blockade were comparable among all 3 groups. Level of peak sensory blockade was T5.87 \pm 1.81 (range T4-T10) in group R, T5.8 \pm 1.91 (range T4-T10) in group RF0.2 and T5.73 \pm 1.63 (range T4-T10) in group RF0.4, which was statistically insignificant (pvalue 0.65$)$. Duration of analgesia was longest in group RF0.4 $(161.17 \pm 10.11 \mathrm{~min})$ compared to group RF0.2 (134.63 $\pm 17.54 \mathrm{~min})$ and group $\mathrm{R}$ $(117.46 \pm 14.28 \mathrm{~min})$ which was statistically significant ( $\mathrm{P}$ value $<0.05)$.

\begin{tabular}{|c|c|c|c|c|c|c|}
\hline Characteristic & Group-R & Group RF0.2 & Group- RF0.4 & & P-valu & \\
\hline & Mean \pm SD & Mean \pm SD & Mean \pm SD & $\begin{array}{c}\mathrm{R} \& \\
\mathrm{RF} 0.2\end{array}$ & $\begin{array}{c}\mathrm{R} \& \\
\mathrm{RF} 0.4\end{array}$ & $\begin{array}{c}\text { RF0.2\& } \\
\text { RF0.4 }\end{array}$ \\
\hline $\begin{array}{l}\text { Onset time of sensory } \\
\text { block(min.) }\end{array}$ & $7.63 \pm 1.13$ & $6.73 \pm 1.86$ & $6.07 \pm 1.51$ & 0.028 & 0.001 & 0.137 \\
\hline $\begin{array}{l}\text { Duration of } \\
\text { block(min.) }\end{array}$ sensory & $95.17 \pm 10.71$ & $105.0 \pm 8.54$ & $122.57 \pm 8.72$ & 0.001 & 0.001 & 0.001 \\
\hline $\begin{array}{l}\text { Onset time of motor } \\
\text { block(min.) }\end{array}$ & $10.4 \pm 1.9$ & $9.13 \pm 1.86$ & $8.8 \pm 1.65$ & 0.511 & 0.02 & 0.011 \\
\hline $\begin{array}{l}\text { Duration of motor block } \\
\text { (min.) }\end{array}$ & $105.5 \pm 12.35$ & $106 \pm 10.43$ & $108.17 \pm 9.01$ & 0.866 & 0.261 & 0.058 \\
\hline Duration of analgesia(min.) & $117.5 \pm 4.28$ & $136.6 \pm 17.54$ & $161.17 \pm 10.11$ & 0.001 & 0.001 & 0.001 \\
\hline Observational Pain Scale & $0.2 \pm 0.41$ & $0.1 \pm 0.31$ & $0.07 \pm 0.25$ & 0.291 & 0.44 & 0.681 \\
\hline $\begin{array}{l}\text { Bromage Scale at the end of } \\
\text { surgery }\end{array}$ & $2.7 \pm 0.31$ & $2.8 \pm 0.48$ & $2.82 \pm 0.47$ & 0.342 & 0.255 & 0.872 \\
\hline $\begin{array}{l}\text { Analgesic consumption } \\
\text { (inj.PCM mg in } 24 \mathrm{hrs} \text { ) }\end{array}$ & $844 \pm 220$ & $\begin{array}{l}754 \pm 197 \\
653 \pm 185\end{array}$ & $653 \pm 185$ & 0.032 & 0.01 & 0.025 \\
\hline
\end{tabular}

Data are expressed as mean \pm standard deviation.

Average taken for Observational Pain score at the end of surgery was less in fentanyl group compared to control group. Mean of bromage scale at immediate post-operative period was comparable in all three groups. There was least In our study no child developed hypotension or bradycardia (defined as decrease of more than $30 \%$ from baseline values) (Graph 1 and 2). One (3.33\%) child in group R, two $(6.67 \%)$ in group RF0.2 and six (20\%) in group RF0.4 complained of nausea and vomiting. Shivering was noted in consumption of rescue analgesic in group RF 0.4 $(653.2 \pm 184.96 \mathrm{mg})$ compared to group RF0.2 $(754.4 \pm 197.31 \mathrm{mg})$ and group R $(843.75 \pm 239.75 \mathrm{mg})$ in first 24 hours postoperative.

$1(3.33 \%)$ patient in group $\mathrm{R}, 2(6.67 \%)$ patients in group RF0.2 and $1(3.33 \%)$ patient in group RF0.4. Incidences of pruritus were $4(13.33 \%)$ and $7(23.33 \%)$ in group RF0.2 and group RF0.4 respectively. No cases of urinary retention. None of the patient visited for complain of PDPH. 


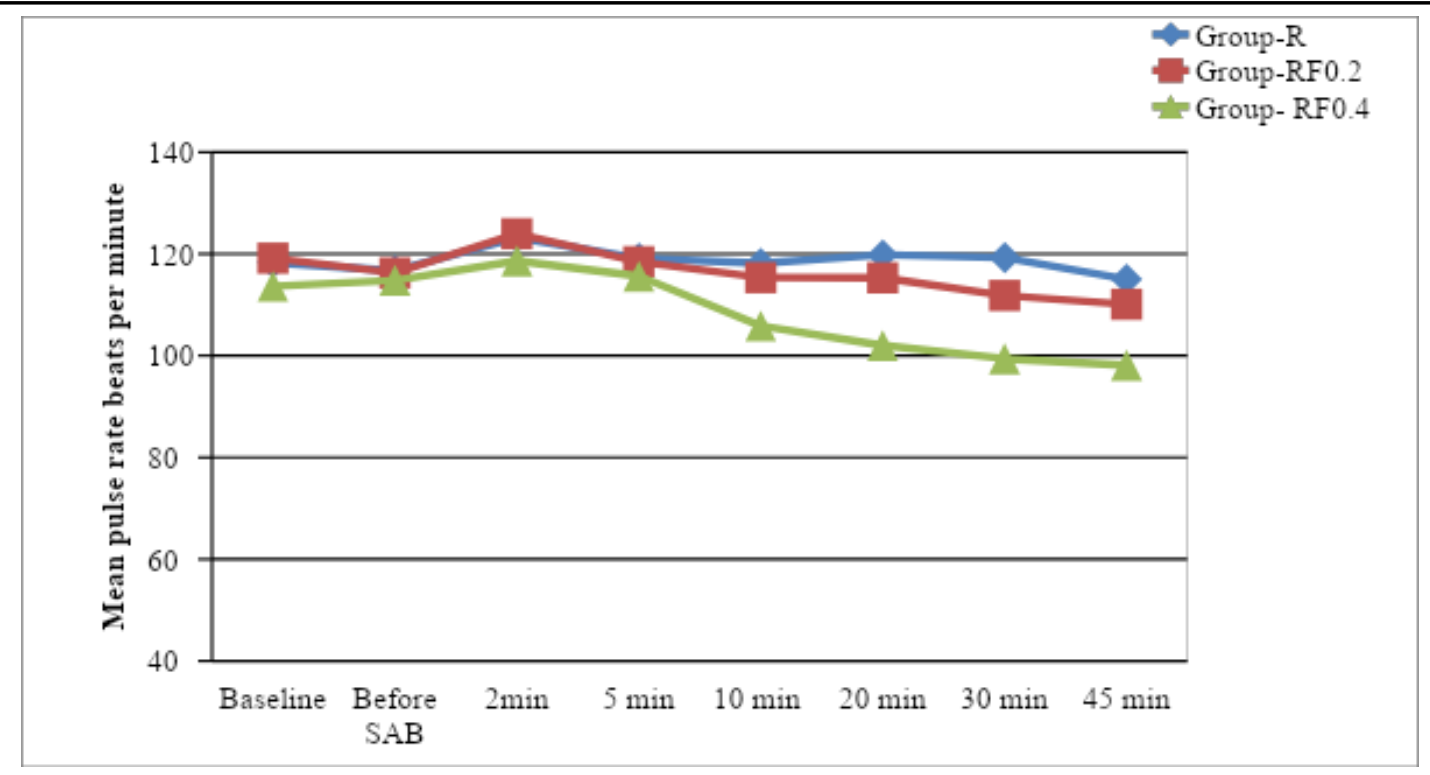

Graph 1: Comparison of mean pulse rate- intraoperative period

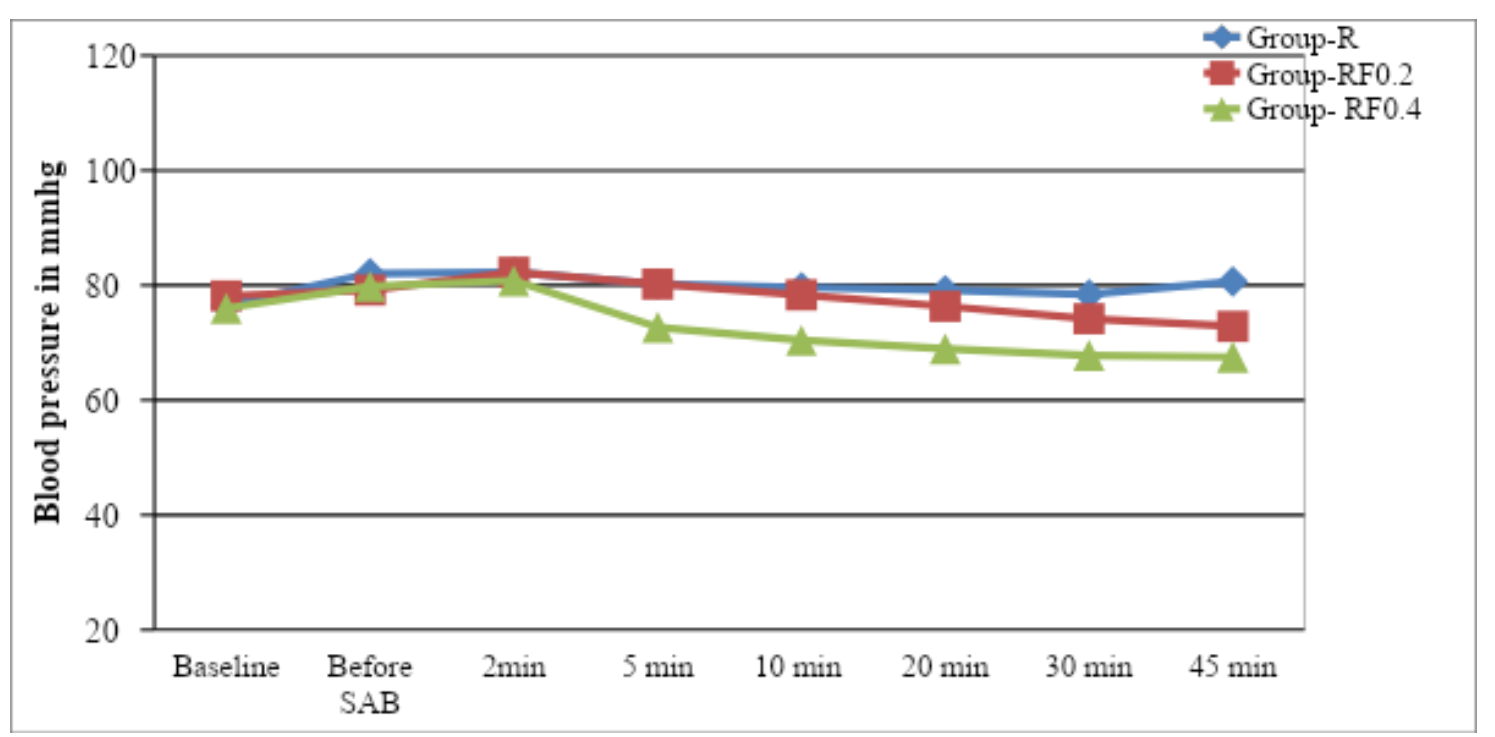

Graph 2: Comparison of mean blood pressure- intraoperative period

\section{Discussion}

As the practice of medicine focuses increasingly on out-patient care, spinal anesthetics should be tailored to provide short acting and adequate anesthesia and analgesia without compromising early ambulation and discharge from the day surgery unit. Ropivacaine is one of the local anesthetics that have potential in this area. Adding an opioid like Fentanyl to the local anesthetic may offer local anesthetic sparing effects and lead to shorter onset time and prolonged duration for sensory block without intensifying motor and sympathetic block of spinal anaesthesia, thus favored for day care surgeries.
In our study spinal anesthesia was successful in $92 \%$ in the first attempt, rest required a second attempt. Frumiento et al. achieved success in $97.3 \%$ in the first attempt in infants ${ }^{6}$, whereas Parthasarathy et al. did in $88 \%$ in children aged 2-12 years ${ }^{7}$. This could be due to possible noncooperation from older children. Better result of our performance may be due to better sedation because slight movement of the children during lumbar puncture can cause failure.

Onset of sensory blockade was fastest in group RF0.4 among all three groups. Onset was faster in group RF0.2 compared to group R. Duration of sensory blockade was longer in group RF0.4 than 
group RF0.2 and in group RF0.2 than group R. Chung CJ et al. $(2002)^{8}$ also found that addition of Fentanyl to Ropivacaine significantly prolonged duration of sensory block. Onset time and duration of motor blockade were comparable among all three groups. Prolonged duration of analgesia was observed in group RF0.4 than group RF0.2 and Group R. Opioids interrupt pain transmission in the dorsal horn, while local anesthetics blocks impulse conduction in the motor and sensory nerves. Therefore, both acts synergistically, lead to shorter onset time and prolonged duration for sensory block. Average taken for Observational Pain score at the end of surgery was less in fentanyl group compared to control group. Total analgesic consumption in first 24 hours was significantly decreased in group RF0.4 compared to group RF0.2 and group R. Dumen A et al. (2010) ${ }^{9}$ found that intrathecal Fentanyl at a dose of $0.2 \mathrm{mcg}$ per $\mathrm{kg}$ added to bupivacaine significantly improves the quality of intraoperative analgesia and prolongs postoperative analgesia in children. There were significant differences in pain scores with lower scores in the Fentanyl group.

Analgesic consumption was less in group RF0.2 compared to group R. No case of hypotension or bradycardia was observed. Puncuh F et al. (2004) ${ }^{10}$ also observed that only 9 of 942 (less than $1 \%$ ) children under 10 years of age developed hypotension in his study. The reason for this may be a less well-developed sympathetic nervous system than adult or lower extremities blood volume that is smaller fraction of total blood volume than in adults. Incidence of nauseavomiting and pruritus increased with higher dose of fentanyl. Ali MA et al. (2018) ${ }^{15}$ also observed that incidences of nausea-vomiting and pruritus were more with higher doses of Fentanyl.

\section{Conclusion}

We concluded that increasing the dose of Fentanyl from $0.2 \mu \mathrm{g} / \mathrm{kg}$ to $0.4 \mu \mathrm{g} / \mathrm{kg}$ as an adjuvant to Ropivacaine improves quality of block and increases duration of analgesia without significant effect on motor block but the incidence of nauseavomiting and pruritus are also increases.

\section{References}

1. Rakhee Goyal, KaRvitha Jirtjil, BB Baj, Sunil Singh, Santosh Kumar: Paediatric Spinal Anaesthesia.Indian journal of anaesthesia: 2008 | Volume : 52 | Issue : 3 | Page : 264-272

2. Finster M: Toxicity of local anesthetics in the fetus and newborn: Bull NY Acad Med1976; 52:222

3. McClure JH1: Ropivacaine.: Br J Anaesth. 1996 Feb; 76(2):300-7.

4. U Bakshi, S Chatterjee, S Sengupta, D Gupta: Adjuvant Drugs In Central Neuraxial Analgesia- A Review. The Internet Journal of Anesthesiology. 2009 Volume 26 Number 1.

5. Mark A. Chancy MD: Side effects of intrathe- cal and epidural opioids: CAN J ANAESTH 1995 / 42:I0 / ppS91-903.

6. Frumiento C, Abajian JC, Vane DW. Spinal anaesthesia for preterm infants undergoing inguinal hernia repair. Arch Surg 2000;135:445-51.

7. Parthasarathy S, Senthilkumar T. Agebased local anesthetic dosing in pediatric spinal anaesthesia: Evaluation of a new formula - A pilot study in Indian patients. Anesth Essays Res 2017;11:627-9.

8. Chung CJ,Yun SH, Hwang GB:Intrathecal fentanyl added to hyperbaric Ropivacaine for cesarean delivery.Reg Anesth Pain Med; 002 Nov-Dec;27(6):600-3

9. Duman A, Apiliogullari S, Duman :. Effects of intrathecal Fentanyl on quality of spinal anaesthesia in children undergoing inguinal hernia repair. Paediatr Anaesth. 2010 Jun;20(6):530-6. doi: 10.1111/j.1460-9592.2010.03315.x. Epub 2010 Apr 23.

10. Puncuh F, Lampugnani E, Kokki H: Use of spinal anaesthesia in pediatric patients: 
A single centre experience with 1132 cases. Pediatr Anesth 2004;14:564-7

11. Ali MA, Ismail S, Sohaib M, Aman A. A double-blind randomized control trial to compare the effect of varying doses of intrathecal Fentanyl on clinical efficacy and side effects in parturients undergoing cesarean section. J Anaesthesiol Clin Pharmacol 2018;34:221-6. 